\title{
The Experimental Research on Stylized Teaching Method Used in the Art Guidance of Chinese Undergraduates (Piano Accompaniment) - Take the Teaching of Haidun Piano Sonata as an Example
}

\author{
Liang Zhou \\ Moscow State Pedagogical University, Moscow, Russia \\ DOI: $10.32629 /$ asc.v2i4.561
}

\begin{abstract}
The major of piano accompaniment has been very popular, but it is very short of the professional director, and the art guidance courses are various. But, the technology and method of piano accompaniment are the compulsory courses however it is divided. In the class and practice activity, stylized teaching must be practiced, which can not only make the students better learn the artistry of the work via the art guidance courses, but it also makes the student have more feelings about the work. In the recent years, the domestic art has been increasingly developing and gradually improved, and piano accompaniment has been a type of profession, which has attracted much attention in the field. Above all, in the paper, it researches and analyses the teaching practice of piano accompaniment to ascertain how to achieve better stylized teaching to indeed improve the quality of art guidance of the Chinese undergraduates, and at the same time to assist Chinese art to get a further development.
\end{abstract}

Keywords: piano accompaniment, teaching practice, stylization, artistry

\section{Introduction}

Different music culture has different unique styles. Therefore, in the process of song accompaniment, it must be stylized, and piano accompaniment, as the most key existence in the stage, should fully show the corresponding art style. From the past teaching experience, we can learn that teachers need to use different teaching methods to improve knowledge of students' professional technology and their level of art in the class. Stylization teaching method can not only create artistic conception atmosphere, but it also involves the undergraduates in the scene, letting them identify with the music work, at the same time, it indeed improves the teaching quality, producing positive effects. What is the most important is that stylized accompaniment is one of the necessary skills, which means that when doing art guidance, teachers must practice stylized teaching method to better help the students of the major, improving their artistic accomplishment.

\section{The necessity of putting stylized teaching method into practice in the art guidance courses}

Art director is a relatively specific profession, at present, which has not drawn enough attention, and most time is presented as the piano accompaniment. To be an artistic director, not only high capacity of playing the piano is required, but also extremely strong artistic sensibility is needed. What is artistic sensibility? It is the ability to grasp the feeling and intension including the whole core and handling method of each melody. An artistic director is most key in the presentation of the work. A good art director can improve the whole expressiveness of the work. For an art director, what is the most necessary is to have a unique performance style.

Music, as a kind of reflecting human real life, is a kind of art to express and it should be comprehensive and abundant. Therefore, in the process of art guidance for Chinese undergraduates, we should not only implement diversified teaching methods, but also comprehensively implement high-efficiency and high-quality teaching method. Piano accompaniment is the fundamental ability that the vocal art director must possess. For the teaching activities of art guidance course, teachers should guide students to master the style, language, sound and other elements of works. Moreover, in the process of piano accompaniment training for Chinese undergraduates, the goal is to master vocal music style and fully implement the stylized teaching method, which is the best means to achieve the teaching goal. At the same time, the implementation of stylized teaching method also plays a great role in promoting the future career of undergraduates, which can greatly improve the quality and efficiency of teaching activities of art guidance courses, and ensure that students can have better artistic ability and artistic literacy. From the perspective of practical teaching concept, with the help of stylized teaching method, piano accompaniment can be given more energy, so that students can gain more in receiving art guidance. From the practical 
teaching experience, both students and teachers can learn much from the stylized teaching method.

Consciously implementing the stylized teaching method in the teaching activities of art guidance course can strengthen the style characteristics of works, make students more clearly understand the emotional style and subject thought behind vocal music works, and realize knowledge breakthrough from the theoretical level. For example, Haydn's Piano Sonata has its unique style, and Haydn's style characteristics are changeable, which can be divided into rococo, gallantry, emotion and so on. Therefore, in the process of piano accompaniment, we should pay attention to emotional expression, so that students can better feel rococo, gallantry, emotion and so on. The implementation of stylized teaching method in the teaching activities of art guidance course can make students better feel the charm of music art and generate learning enthusiasm and interest. Moreover, stylized teaching method can improve the practical value of teaching activities of art guidance course, strengthen students' practical application ability, including the stage control ability, stage actual performance ability and emergency handling ability, and form performance skills, which cannot be achieved by traditional teaching methods. In a word, stylized teaching method with the piano accompaniment plays an important role in improving students' comprehensive ability and quality. It can also further improve students' artistic quality, which plays an auxiliary role in their future career. In addition, stylized teaching method with the piano accompaniment also plays a certain role in improving the quality of students' spiritual civilization. Students can further feel the emotional connotation behind the song, so as to become new talents to meet the needs of the society.

\section{Key points of implementing stylized teaching method in teaching activities of art guidance course}

The essence of art guidance lies in the perfect grafting between technical functions such as work analysis, stage performance and band conductor and piano accompaniment, so as to show piano art and performance ability. Through the course and practice activities, the goal of the art guidance course is to develop the knowledge and skills about the organization mode, composition, historical analysis and their interaction of music, and deeply understand its professional field, aesthetics and related styles.

\subsection{Clarify the style of the works with the help of the background of the times}

It can be seen from the above that with the help of stylized teaching method, students can better feel the artistic charm behind music works, stimulate students' perception ability of works, and then interpret works more thoroughly in actual performance, and even integrate into the process of reproduction of works wholeheartedly. In other words, the stylized teaching method can further enhance students' perception ability. However, it should be noted that in the process of practical implementation, the stylized teaching method needs to be combined with the actual works and take the style characteristics of Haydn's Piano Sonata as an example. In the teaching process, teachers should start from the background of the times to make students have a profound understanding of the three styles. First, rococo style became popular in Europe in the 1820s. It is characterized by: delicate, gorgeous, exquisite, complex and trivial. It began with the construction style of the French court. It is used for music creation, showing nobility and elegance. Accompanied by the ancient piano, it has caused a sensation in the society and is deeply loved by the audience. However, influenced by many complex factors in the society at that time, this style did not form a school and passed on to future generations. Second, the gallant style is derived from the rococo style. The "gallantry" refers to the music style respected by the upper class. A large number of decorative sounds are often used in detail processing, which sounds very grand. But at that time, the audience was eager to feel the emotional flow around them in the music, so they had their own characteristics in form and content. The music style was very exquisite in relaxed, concise, lively and natural. Third, emotional style, called "passion style", is more accurate. It presents an explosive emotional expression effect with strong passion. It not only pays attention to the exquisite degree of external decoration, but also pays attention to internal affection. Haydn's Piano Sonatas cover three styles, but because the gallant style is of great significance to the formation and development of Sonatas, most of his creations tend to be gallant style without losing humor.

\subsection{Key points of performance according to the style of the work}

Piano is the most famous of Western classical musical instruments, known as the "king of musical instruments". Different repertoires played by a piano can bring unique emotional expression and performance characteristics to the audience; sometimes they sound bright and fresh, sometimes high and heroic, sometimes gentle and soothing and sometimes like angry waves howling. Because of this, piano performance always maintains great creative freedom. Teachers should guide students to understand music playing skills from a macro perspective in class, and flexibly control playing skills. For example, when playing Haydn's Piano Sonata, we should not only combine Haydn's growth environment and living environment, but also combine the creative background of Baroque period, fully grasp the key points of performance and 
deeply feel the emotional connotation in Haydn's works. Teachers must realize the significance of stylized teaching method for improving the teaching quality of music course. As a participant in music works, art guidance is not only the key to ensure the stable presentation of music works, but also undertake the overall performance effect. At the same time, students must also be deeply aware of the responsibility of art guidance on the stage. Teachers should set an example, maintain a rigorous attitude in the stylized teaching method, standardize students' performance behavior, let students realize their own shortcomings, and treat each performance activity with a correct attitude. For example, when playing, the mastery of legato, the processing of passing tone and skipping tone must be very accurate, and the details should be carefully studied to understand the advantages and disadvantages of different ways of playing. Haydn's emotion is high, and the player must put more enthusiasm into the performance to move the audience. Not only that, you should keep a relaxed attitude when playing. Remember not to memorize the music scores, resulting in stiff movements. Every joint of a music player is an emotional release signal. Only when you relax and "touch" the button with your heart can you play a full tune.

\subsection{Style cognition with different activities}

In addition to the above contents, it is found in the actual survey that most students have less practical experience. In this case, even if the stylized teaching method is carried out, the effect is very limited. After investigation and analysis, it is found that some students are not willing to participate in practical activities because they are not confident in their own strength, are afraid of facing criticism and are worried that their performance is not good enough. Therefore, to maximize the teaching effect of the stylized teaching method, it is necessary to encourage students to participate in different activities. When students participate in extracurricular activities, two teachers act as instructors to provide help to students anytime and anywhere. In school activities, corresponding teachers also carry out mobilization meetings, provide guidance and help to each group or individual participating in the activity. In this way, some students with weak self-confidence can actively participate in the activities with the encouragement of teachers, and can also recognize their own shortcomings and make continuous improvement. Only in the actual teaching activities can the students better feel the performance style. In addition, the school can encourage students to actively build different types of music and art associations, give them some autonomy, let students' associations carry out different activities independently, and provide them with some help. This can not only create a good campus art atmosphere, but also improve students' quality and ability in other aspects.

\section{Conclusion}

In conclusion, in today's all-round development of quality-oriented cultural education, in the process of music training, realizing the stylized teaching method and comprehensively strengthening the teaching characteristics of piano accompaniment education can sublimate and improve the music knowledge and practical skills of undergraduates, fundamentally meet the actual development needs of teaching activities of music guidance courses, and truly implement quality-oriented cultural education. Different music works have different styles, but the style itself is an abstract content, which requires teachers to visualize this style with the help of different guidance methods, so that students can truly feel the infinite charm of music.

\section{$\underline{\text { References }}$}

[1] Shi X. Research on piano teaching method - Comment on the training guidance of piano teaching method theory and techniques (in Chinese). Higher Education Exploration, 2018; (5): 135.

[2] Liang Y, Liu Q. Artistic guidance of piano accompaniment in vocal music teaching (in Chinese). Art Evaluation, 2019; (11): 86-88.

[3] $\mathrm{Hu}$ M. Analysis on the artistic guidance of piano accompaniment in vocal music teaching in Colleges and universities (in Chinese). Home Drama, 2021; (27): 99-100.

[4] Liu N. On the artistic guidance of piano accompaniment in vocal music performance teaching (in Chinese). Charming China, 2020; (29): 112-113. 